\title{
Introduction: Charting Provocations and Exploring New Directions for Pacific Research in Aotearoa-New Zealand from Pacific Early Career Academic (PECA) Perspectives
}

\author{
Seuta'afili Patrick Thomsen, Lana Lopesi and Marcia Leenen-Young
}

"Uplifting Moana Perspectives: Emerging Pacific Researchers and New Directions in New Zealand-Based Pacific Research" presents a shared vision for the future of Pacific research by Pacific early career academics (PECA) primarily based in Aotearoa-New Zealand. The task of charting new directions in imagining possibilities for Pacific research is a critical one, which speaks to our communities' long and storied history in Aotearoa: a reality incongruent with the lack of Pacific scholars employed in permanent positions in New Zealand universities. ${ }^{1}$ This special issue challenges the idea that there is a dearth of Pacific research, asserting rather that our underrepresentation in academia is a structural issue, not necessarily one of scarcity. ${ }^{2}$ As special issue editors, we intentionally draw in a cross-section of emerging Pacific researchers in our country to confidently write with emerging Pacific scholars on the other side of our MoanaOceania region, writing back to the exclusionary nature of conventional disciplinary norms and divides that we are forced to navigate. In doing so, our contributors challenge and transcend disciplinary boundaries and push against the Eurocentrism of our tertiary education system. This work is crucial, as the ability to build an academy that prioritises and centres our ways of knowing, doing, relating, and being is a key component of addressing cultural safety and inclusiveness in university lecture theatres, curriculums, and epistemological norms for both PECA and Pacific students in Aotearoa-New Zealand. ${ }^{3}$

The foundation of this special issue came from the establishment of the first Pacific Early Career Academic Network (PECAN) at the University of Auckland. PECAN is a collective of early career academics of Pacific heritage from various schools, faculties, and disciplines across the university. While many non-Pacific academics have made valuable contributions to Pacific scholarship, within the context of PECAN — and similarly with the context of this special issue - a PECA first and foremost carries Pacific whakapapa, which as discussed throughout this issue comes with its own unique opportunities and challenges in the university. PECAN members all share in a vision that uplifts and empowers space to collectively support each other and acknowledge our unique needs as PECA. Our network was formed by PECA for PECA and with PECA leading the way. It is a space of strategy, awareness, and collective ambition to support each other through the difficulties of academic life. It is also a space for sharing, venting, problem solving, eating, and laughing - a lot. A kind of oasis within the stress and pressure of an academic life that we were all warned about, but which in many ways we are encountering and making sense of from within our own realities as Pacific scholars. For many of us, we are doing so for the first time. ${ }^{4}$

This call for community has informed this special issue in important ways. All our contributors have chosen to commit their work to questions of Pacific inclusion and innovative transformation. Some contributors focused specifically on the process of remaking the academy. ${ }^{5}$ Others chose to explore possibilities of disciplinary transcendence in centring Pacific worlds. ${ }^{6}$ A final set of

Journal of New Zealand Studies NS33 (2021), 1-9 https://doi.org/10.26686/jnzs.iNS33.7378 
contributors focused on pushing the frontiers of Pacific research by drawing out productive tensions in respectfully transgressing binaries and boundaries that have reached their natural limits, intentionally crafting more inclusive Pacific research agendas. ${ }^{7}$

Although initially envisioned as a special issue in which we as emerging Pacific researchers at the University of Auckland would offer our own research(er) reflections on the state of Pacific research in Aotearoa-New Zealand, we have come to embrace the interconnectedness of our own lineages with our Pacific colleagues in other universities and even in other parts of the world. This special issue brings together perspectives from scholars based in Hawai' $i$, the United States, and Australia, bringing them into conversation with our own perspectives, and acknowledging again the interwoven nature of Pacific genealogies and the generative possibilities this can offer in nuancing and enhancing our Pacific scholarship based here in Aotearoa. Ultimately, it is the New Zealand Pacific and other diasporic contexts that we write from. All contributions should be read generously from within this specific context. The voices that come together here are making sense of what Pacific worlds mean to them on the edges; they do not intend to speak on behalf of our vast, heterogenous, and rich region in the centre, from where our whakapapa derives.

Even though Pacific scholarship has grown in many fields in New Zealand, there has been little opportunity given to emerging Pacific scholars to explore issues of transdisciplinarity framed by their shared experiences of being New Zealand-based scholars. Furthermore, little space has been given for us as early career researchers to map out exactly, from our perspectives, what it is that makes doing Pacific research in New Zealand today unique. This special issue shares much of what we know to be true already (our Pacific research community is heavily Polynesian-centric, dominated by Sāmoa and Tonga; it is located in and focused on the diaspora), but also presents new possibilities in routing and rerouting Moana-Oceania connections: in diversifying epistemological approaches; in suturing or to su'i (sew) together seemingly disconnected and disparate Pacific realities to energise new ways of seeing who we are and the cosmopolitan worlds we all imagine, inhabit, and work through as emerging Pacific scholars. ${ }^{8}$

As such, some unique editorial decisions were made that may contradict certain norms of the inhouse editing style for this journal. We offer our deep and appreciative gratitude to Professor Anna Green and Dr Dougal McNeill, who provided space for us to explore these possibilities in centring our perspectives and standpoints. As guest editors for this special issue, we made the decision to not italicise all Pacific terms and words from our Pacific languages. This practice is becoming more common in New Zealand around normalising the use of Te Reo Māori; we intentionally engage this to encourage the normalisation of Pacific worlds and ways of knowing, as representative of the connections and genealogies we make possible in Aotearoa nei. Furthermore, we intentionally make use of the glottal stop and macrons across the entire issue to denote Indigenous Pacific terms and words as they are meant to be pronounced. We do not, however, use these grammatical functions to Indigenise English descriptors of our peoples and knowledges. Thus, Sāmoa receives a macron whilst Samoan does not, as Sāmoa is an Indigenous Pacific term and Samoan is an English label that serves a colonial purpose. The same grace is extended to Hawai' $i$, and not Hawaiian for similar logics.

Journal of New Zealand Studies NS33 (2021), 1-9 https://doi.org/10.26686/jnzs.iNS33.7378 
Also, to honour the multifaceted ways Pacific people refer to who we are as a diversely positioned pan-Oceanic collection of communities, differentiated by our own unique region- and culturespecific experiences, we acknowledge the multiple terms used to denote our region and our connections to its knowledge genealogies. Throughout the issue, contributors will refer to the Pacific, Pasifika, Moana, Moana-Oceania, Oceania, Moananui-a-Kiwa using various spellings, to illustrate the multitude of ways our peoples see and refer to our region. Although we as special editors commonly use Pacific in the Aotearoa-New Zealand context, we have deliberately chosen not to edit for consistency across the papers; rather, we choose to celebrate the multiplicity that these terms offer. We recognise that they represent knowledge lineages and political potentials of their own. As editors of this special issue, we also wish to thank the Office of the Pro ViceChancellor Pacific at the University of Auckland, specifically Toeolesulusulu Associate Professor Damon Salesa and Sili Mireta Pita, whose advocacy, resourcing, and encouragement has been pivotal to the formation of PECAN and ultimately helped us to work across disciplinary divides to bring this special issue to life.

\section{Our Peer Review Process: Modelling a Pacific Values-Based Approach}

As so few Pacific scholars are tenured as permanent academics within New Zealand universities, the peer review process for us can be fraught with culturally unsafe and unsavoury experiences, as journals often send our work to reviewers of non-Pacific heritage both here and abroad. ${ }^{9}$ These reviewers are not usually positioned appropriately to be able to situate and critique our scholarship within the cultural contexts and knowledge systems in which they are produced. These inherent biases structure the entire peer review process in a way that often excludes Pacific and Indigenous ways of knowing. ${ }^{10}$ Many of us have experienced what can be described as racist, biased and unbalanced reviews, which can not only frustrate and distract us from producing great scholarship, but it can also slow down our publishing potential. ${ }^{11}$

Furthermore, Pacific academic epistemological communities are still rather sparsely populated, as we are underrepresented in academia. ${ }^{12}$ This often makes an anonymous peer review process difficult to ensure without turning to non-Pacific and non-Indigenous expertise. Also, when we are requested to provide reviews on Pacific manuscripts, as one of the few Pacific scholars in our disciplines, it often quickly becomes obvious whose work we are reviewing despite manuscripts being anonymized by editorial teams. This creates a dilemma: we carry an awareness that if we refuse to review a Pacific manuscript, the journal is likely to approach a non-Pacific or nonIndigenous reviewer, which runs the risk of shifting the cultural hazards onto another Pacific colleague. It is obvious that this situation can be unsafe for emerging Pacific scholars in many ways. In particular, not having the opportunity to dialogue with a more senior Pacific colleague face-to-face can harm relationships when criticism of their work is offered outside of a vā setting, removing the impetus for the mana of all to be preserved without a direct interaction. This is a major concern, as the relationship with senior peers is often critical in modelling and developing career pathways for Pacific academics in a highly competitive and Eurocentric profession. ${ }^{13}$ The need for good relations is a critical piece for us as Pacific academics, as relationality is often touted as forming the bedrock of Pacific research ethics and praxis. ${ }^{14}$

As such, the editors of this special issue made the decision to model a Pacific, collegial and inclusive form of peer review, ensuring all manuscripts would be scrutinised to the highest

Journal of New Zealand Studies NS33 (2021), 1-9 https://doi.org/10.26686/jnzs.iNS33.7378 
standards and rigour expected of scholars in academia without sacrificing what it is that makes unique who we are and what we do as Pacific researchers in the academy. All members of PECAN were invited to submit an article. For scheduling reasons, not all were able to complete a submission, and many chose to work collaboratively, but all worked with an implicit understanding that we as an editorial team and group would work with contributors to make sure their articles would be ready to appear in this edition of the Journal of New Zealand Studies. This immediately ensured that none of the scholars featured here would have to write from a place of paranoia, as there was no attempt to gatekeep their work, but rather only the desire to elevate it through the review process. This was important for us as editors, as our goal was to encourage our contributors to test the limits, boundaries, and possibilities of research in their disciplines to approach generatively the task of imagining what we could produce together, across disciplinary lines. Although the expectation in academic publishing is that all reviewers produce reports that are supportive and designed to improve submitted work, the reality is very different for scholars of non-Western knowledge traditions. ${ }^{15}$ Unconscious bias in the review process often dismisses submissions from scholars working from knowledge systems not of the Global North. ${ }^{16}$ In contrast, reviewers for our special issue often reported taking more concerted time to construct and frame reviewer reports that were expressly designed to build contributors' confidence in navigating a process that can be obstructive. They also reported a keen desire to support emerging Pacific scholars' work, and ascribed to and remained highly cognisant of the critical need to get more high-quality Pacific scholarship published, facilitating a review praxis free of the hermeneutics of suspicion, akin to what Eve Sedgwick calls "reparative reading," finding the potential in advancing the development of Pacific emerging scholars" work. ${ }^{17}$

All papers that appear in this special issue have been double peer reviewed, with the authors nominating an external senior peer reviewer from within their disciplinary field (all from Moananui-a-Kiwa) to complete an evaluation of their manuscripts. From these nominations, the editorial team selected the appropriate expert reviewer. In addition, manuscripts were also sent to reviewers who were Pacific contemporaries and had expertise in the subject matter or area that contributors were positioning their papers within. This was to ensure that not only was Pacific expertise reviewing Pacific expertise, but that the goal of moving beyond disciplinary divides was facilitated by multiple (Pacific) disciplinary perspectives. The authors were also given the option of allowing their peer reviewers to provide ongoing dialogue after the review submission, a process that contributors agreed to before submitting their papers. A few contributors did take up this option by communicating through the editorial team; a great deal many more, however, chose to process their reviewer comments in the conventional manner, but with a much more constructive and generative energy, avoiding paranoia while ensuring quality, rigour, and Pacific knowledges were given their fullest consideration in this process.

The end result is a set of articles that we are proud to present as a cross section of the exciting research, intellectual thinking, and disciplinary innovations that emerging Pacific researchers are providing in our country and abroad today. As a first move (of what we hope will be many) toward exploring emerging Pacific scholarly potential in this way, these papers are rigorous, imaginative, push back against disciplinary norms, and transcend unproductive boundaries. We hope that they may also give the next generation of Pacific scholars in New Zealand the permission to allow 
themselves to think in transgressive ways, productively, in pushing lines and expanding directions in Pacific research to make new pathways for us all.

\section{Transforming, Transcending, and Transgressing}

The contributions within this special issue each conceive new directions for Pacific research, where three clear themes emerged: transforming the academy; transcending disciplinary pressures; and transgressing disciplinarity. For Pacific knowledge and in turn Pacific academics to be genuinely valued within the University system, there is transformation that needs to occur. Tim Baice, Sereana Naepi, Seuta'afili Patrick Thomsen, Karamia Muller, Marcia Leenen-Young, Sam Manuela and Sisikula Sisifa write together to open this special issue. Drawing on data and lived experiences, the authors engage in a thematic talanoa to humanise the perpetual underrepresentation of Pacific early career academics, and the epistemological hierarchies that are felt lived experiences and not merely an intellectual exercise. The stakes are high for PECA, as our presence in the academy disrupts the foundational whiteness of universities. ${ }^{18}$ Fittingly, the paper was also the first collaboration between PECAN members. It thus represents the genesis point of this special issue and marks out the beginnings of the network. Sereana Naepi in her solo contribution continues this reformational energy, arguing for the need to transform the academy by outlining what interventions are being made to increase Pacific engagement in Aotearoa-New Zealand's universities. ${ }^{19}$ While Naepi asserts that there are levers of change in operation, they do little to create the significant level of structural change needed for genuine transformation. Rather, if we want to move beyond the glacial institutional change we are currently witnessing, we need to understand the value of Pacific bodies within the university.

As a consequence of the whole university descending from Eurocentric traditions, many PECA find themselves forced to develop their own strategies to push against the dominant schools of thought within their area of expertise, to make room for Pacific ways of knowing, and by extension their own Pacific bodies. Marcia Leenen-Young considers this within the highly Eurocentric_-and Eurocentrically governed-discipline of history. Leenen-Young explores the tensions implicit in Pacific history, which they note is a tool of imperialism that silences and controls, arguing for a need to prioritise history that centres the voices of Pacific peoples. This also requires an understanding of what the absence of Indigenous Pacific historians means for Pacific peoples and communities as a whole. ${ }^{20}$

Likewise, Dylan Asafo and Litia Tuiburelevu collectively offer their critical reflections on Pacific legal scholarship, naming the structural barriers preventing the production of this important work. They acknowledge the invisible labour many Pacific academics perform through service roles, roles which see many PECA overwhelmed and unable to focus on developing their own scholarship. The pair conclude by offering a Pacific jurisprudence that centres "collective wondering and possibilities that exist outside of the institutional dogma." 21 Sisikula Sisifa and 'Ilaisaane Fifita similarly acknowledge the barriers of invisible labour, shifting our examination to the business academy, by also problematising the tokenism ascribed to Pacific methodologies in their field. ${ }^{22}$ For Sisifa and Fifita, who in their pairing account for half of all permanent Pacific academics in the Business School at the University of Auckland, the business academy is a complex system reinforced by colonial power structures, presenting many constraints on and drivers to using Pacific methods such as talanoa in business.

Journal of New Zealand Studies NS33 (2021), 1-9 https://doi.org/10.26686/jnzs.iNS33.7378 
Moeata Keil shifts the spotlight to social science research, addressing a question that has been for so long deferred in Pacific research, but nonetheless implicitly known: how do we navigate the gendered complexities of talanoa? All authors in this special issue emphasise the importance of positionality as Pacific researchers, but Keil highlights the additional need for gendered positionality to be acknowledged within the talanoa framework. Their contribution raises vital questions about whether Pacific researchers can genuinely and meaningfully engage in talanoa across gendered contexts, while still adhering to and being guided by cultural principles, protocols, and practices. Keil asks whether this is a transgression of gendered relational space. ${ }^{23}$

The contribution from Seuta'afili Patrick Thomsen and Joshua Iosefo-Williams follows Moeata Keil's in offering a provocation for Pacific research by forcing us to grapple with the issue of queerness and non-normative ways of knowing and being in the world. In doing so, their contribution intentionally transgresses disciplinarity as a priori for generating an inclusive Pacific research futurity in Aotearoa-New Zealand. Thomsen and Iosefo-Williams write as two queer Samoan scholars, revealing the way that Pacific research is dominated by heteronormative boundaries that refuse to accept the complexity of Pacific queer life. By reflecting on their own separate and intimate experiences within and outside the academy, Thomsen and Iosefo-Williams make clear that the Pacific academy as it stands needs to contend with the ways in which it reinforces systems of oppression, if it is to be as inclusive of all Pacific experiences as it claims to be. $^{24}$

David Taufui Mikato Fa'avae, Edmond Fehoko, Sione Siu'ulua and Finausina Tovo challenge accepted intellectualisations within the academy that favour the false notion of objectivity. Through critical autoethnographic reflections and talatalanoa, the authors collectively assert an alternative intellectual project of becoming creatively critical through deep engagement with Tongan language, knowledge, and cultural practices. This, according to the authors, energetically triggers and inspires the resistance work necessary for academic survival. ${ }^{25}$ In the following paper, Lana Lopesi argues that part of this resistance work is the need for transdisciplinary theorising to extend knowledge and move beyond disciplinary decadence and self-essentialising tendencies. Pacific researchers as transdisciplinary actors provide fertile ground for developing Pacific theoretical thinking, and interventions that offer new ways of seeing and understanding the world around us. Lopesi suggests su'ifefiloi using the 'ula lole metaphor as a reparative methodology, attuned to the materiality and cosmopolitan reality we are ensconced within as Pacific peoples, moving us toward collective and abundant futures. ${ }^{26}$

Walking backward into the future, and forward into the past, the article section ends, much as it began, with a collective effort to link past knowledges with the potential of the future in the here and now. The final substantive contribution is a collaborative effort that engages new directions and concerns for PECA in the age of curated social media, digital and augmented realities. Once again engaging with thematic talanoa as a Pacific-grounded relational research praxis, ${ }^{27}$ Seuta'afili Patrick Thomsen, Lana Lopesi, Gregory Pōmaika‘i Gushiken, Leah Damm, Kevin Lujan Lee, Emmaline Pickering-Martin, Fetaui Iosefo, Sereana Naepi and Litia Tuiburelevu outline how sites such as Twitter can be activated as a digital vā, offering marginalised Pacific scholars from within Pacific communities generative possibilities to congregate, connect, strategize, and resist online. ${ }^{28}$

Journal of New Zealand Studies NS33 (2021), 1-9 https://doi.org/10.26686/jnzs.iNS33.7378 
This special issue is closed by a storied reflection piece from Roannie $\mathrm{Ng}$ Shiu, supported by the poetics of Fetaui Iosefo. In a raw, honest and personal account of her malaga faigatā, or difficult journey in the academy, to her current position as a mid-career accidental academic, $\mathrm{Ng}$ Shiu urges us to accept that complexities are inherent to diasporic Pacific realities. The piece speaks to the unique criticalities - which include an equity tax and a complicated relationship to Pacific studies and Pacific research in general - that impact decision-making around staying in an academy that has traditionally held back space from our communities and scholars. These complex criticalities can lead to generative and sometimes happy (and not so happy) accidents, which have taken $\mathrm{Ng}$ Shiu around the world in service of Samoan and Pacific communities.

For us as PECA, this special issue does more than centre our voices in Aotearoa-New Zealand. All contributors offer provocations and prescribe directions that our work can take in transforming the academy, in transcending disciplinary decadence, in transgressing confining binaries and essentialisms. We offer this special issue as a way to open constructive dialogue and reflection on where to next for the journey of Pacific research in Aotearoa-New Zealand, as we make, remake, and reconfigure our imagined and constructed Pacific worlds in preparation for the next iteration of the Pacific story. It is a story tied to lineages and routes across the great Moana-Oceania region, while we continue to write our realities into existence, breathing new life into the academy and intentionally making space for more rising Pacific scholars to join us in helping to build a Pacific academy of our own making.

Journal of New Zealand Studies NS33 (2021), 1-9 https://doi.org/10.26686/jnzs.iNS33.7378 
${ }^{1}$ Sereana Naepi, “Why Isn't My Professor Pasifika? A Snapshot of the Academic Workforce in New Zealand Universities," MAI Journal: A New Zealand Journal of Indigenous Scholarship 8, no. 2 (2019): 219-34; Sereana Naepi et al., "The Pakaru 'Pipeline': Māori and Pasifika Pathways Within the Academy,” The New Zealand Annual Review of Education 24 (2019): 142-59.

${ }^{2}$ Cash Ahenakew and Sereana Naepi, "The Difficult Task of Turning Walls into Tables," in Sociocultural Realities: Exploring New Horizons, ed. Melinda Webber, Sonja Macfarlane, and Angus Macfarlane (Christchurch, New Zealand: University of Canterbury Press, 2015), 181-94; Joanna Kidman and Cherie Chu, "We're Not the Hottest Ethnicity': Pacific Scholars and the Cultural Politics of New Zealand Universities," Globalisation, Societies and Education 17, no. 4 (2019): 489-99; Sereana Naepi et al., "A Cartography of Higher Education: Attempts at Inclusion and Insights from Pasifika Scholarship in Aotearoa New Zealand," in Global Teaching, Education Dialogues With/in the Global South, ed. Carol Reid and Jae Major (New York: Palgrave Macmillan, 2017): 81-99.

${ }^{3}$ Patrick Thomsen et al., "In Our Own Words: Pacific Early Career Academics (PECA) and Pacific Knowledges in Higher Education Pedagogical Praxis," Higher Education Research and Development 40, no. 1 (2021): 49-62; Patrick Thomsen et al., "Practising Pacific Pedagogies During New Zealand's Level Four Lockdown: Pacific Early Career Academics and COVID-19," Waikato Journal of Education 26 (2021): 149-61; Marcia Leenen-Young et al., "“Pillars of the Colonial Institution Are Like a Knowledge Prison': The Significance of Decolonizing Knowledge and Pedagogical Practice for Pacific Early Career Academics in Higher Education," Teaching in Higher Education (May, 2021): 1-16, https://doi.org/10.1080/13562517.2021.1928062.

${ }^{4}$ Tim Baice et al., "Developing Our Voices: Pacific Early Career Academics' Journeys in Aotearoa-New Zealand," in this issue.

${ }^{5}$ Baice et al., "Developing Our Voices"; Sereana Naepi, "Shifting Tides: The Potential and Limitations of Critical Mass to Change Discipline Research Habits," in this issue.

${ }^{6}$ Marcia Leenen-Young, "'Guardians' of Signatures? Future Directions in Pacific History from a Pacific Early Career Academic in Aotearoa," in this issue; Dylan Asafo and Litia Tuiburelevu, "Finding Our Way to the Island: Critical Reflections from Two Emerging Pacific Legal Academics in Aotearoa," in this issue; Sisikula Sisifa and "Ilaisaane Fifita, "Burdened in Business: Pacific Early Career Academics Experiences with Promoting Pacific Research Methodologies in the Business Academy," in this issue; Moeata Keil, "Navigating Gendered Relational Space in Talanoa," in this issue.

${ }^{7}$ Patrick Thomsen and Joshua Iosefo-Williams, "Disruptions, Decolonial Desire and Diaspora: A Provocation Toward a Pacific Queer World-Making Scholarly Practice in Aotearoa-New Zealand," in this issue; David Taufui Mikato Fa'avae et al., "Poetic Deviances, Lessgo Deconstruct the Master's Tools: Creatively Critical Talanoa Mālie and Critical Autoethnographic Defiance," in this issue; Lana Lopesi, "Su 'ifefiloi: A Samoan Methodology for Transdisciplinary Theorising in Cosmopolitan Worlds," in this issue; Patrick Thomsen et al., "Negotiating Digital Vā: Emerging Pacific Scholars and Community Building on Twitter," in this issue.

${ }^{8}$ Lana Lopesi, "Moana Cosmopolitan Imaginaries: Toward an Emerging Theory of Moana Art" (PhD thesis, Auckland University of Technology, 2021); Patrick Thomsen, Lana Lopesi, and Kevin Lujan Lee, "Settler Colonial Citizenship, Upward Mobility and Transnational Pacific Identities," forthcoming in The Contemporary Pacific.

${ }^{9}$ Sisifa and Fifita, "Burdened in Business."

${ }^{10}$ Vanessa Selak, Rod Jackson, and Matire Harwood, "Racism in the Academic Editorial Process," ETangata, 12 September 2020, https://e-tangata.co.nz/comment-and-analysis/racism-in-the-academiceditorial-process/.

${ }^{11}$ Sisifa and Fifita, "Burdened in Business."

${ }^{12}$ Naepi, "Why Isn't My Professor Pasifika."

Journal of New Zealand Studies NS33 (2021), 1-9 https://doi.org/10.26686/jnzs.iNS33.7378 
${ }^{13}$ Thomsen et al., "In Our Own Words."

${ }^{14}$ Patrick S. Thomsen, "Coming-out in the Intersections: Examining Relationality in How Korean Gay Men in Seattle Navigate Church, Culture and Family through a Pacific Lens," Journal of Homosexuality 68, no. 6 (2021).

${ }^{15}$ Sisifa and Fifita, "Burdened in Business."

${ }^{16}$ Jane Onken, Lin Chang and Fasiha Kanwal, "Unconscious Bias in Peer Review," Clinical Gastroenterology and Hepatology 19, no. 3 (2021): 419-20; Charles Leslie, "Scientific Racism:

Reflections on Peer Review, Science and Ideology," Social Science and Medicine 31, no. 8 (1990): 891905.

${ }^{17}$ Eve Kosofsky Sedgwick, "Paranoid Reading and Reparative Reading; Or, You're So Paranoid, You Probably Think This Introduction Is About You," in Novel Gazing: Queer Readings in Fiction, ed. Eve Kosofsky Sedgwick (Durham: Duke University Press, 1997), 1-37.

${ }^{18}$ Kidman and Chu, "We Are Not the Hottest Ethnicity."; Naepi et al., "Pakaru Pipeline."

${ }^{19}$ Naepi, "Shifting Tides."

${ }^{20}$ Leenen-Young, "'Guardians' of Signatures."

${ }^{21}$ Asafo and Tuiburelevu, "Finding Our Way to the Island."

${ }^{22}$ Sisifa and Fifita, "Burdened in Business."

${ }^{23}$ Keil, "Navigating Gendered Relational Space in Talanoa."

${ }^{24}$ Thomsen and Iosefo-Williams, "Disruptions, Decolonial Desire and Diaspora."

${ }^{25}$ Fa'avae et al., "Poetic Deviances, Lessgo Deconstruct the Master's Tool."

${ }^{26}$ Lopesi, "Su'ifefiloi."

${ }^{27}$ Patrick Thomsen, "Transnational Interest Convergence and Global Korea at the Edge of Race and Queer Experiences: A Talanoa with Gay Men in Seoul," Du Bois Review: Social Science Research on Race 17, no. 20 (2020): 411-28.

${ }^{28}$ Thomsen et al., "Negotiating Digital Vā." 